\title{
Acute effects of foam rolling on passive tissue stiffness and fascial sliding: study protocol for a randomized controlled trial
}

\author{
Frieder Krause*, Jan Wilke, Daniel Niederer, Lutz Vogt and Winfried Banzer
}

\begin{abstract}
Background: Self-myofascial release (SMR) aims to mimic the effects of manual therapy and tackle dysfunctions of the skeletal muscle and connective tissue. It has been shown to induce improvements in flexibility, but the underlying mechanisms are still poorly understood. In addition to neuronal mechanisms, improved flexibility may be driven by acute morphological adaptations, such as a reduction in passive tissue stiffness or improved movement between fascial layers. The aim of the intended study is to evaluate the acute effects of SMR on the passive tissue stiffness of the anterior thigh muscles and the sliding properties of the associated fasciae.

Methods: In a crossover study design, 16 participants will receive all of the following interventions in a permutated random order: (1) one session of $2 \times 60$ s of SMR at the anterior thigh, (2) one session of $2 \times 60 \mathrm{~s}$ of passive static stretching of the anterior thigh and (3) no intervention. Passive tissue stiffness, connective tissue sliding, angle of first stretch sensation, as well as maximal active and passive knee flexion angle, will be evaluated before and directly after each intervention.
\end{abstract}

Discussion: The results of the intended study will allow a better understanding of, and provide further evidence on, the local effects of SMR techniques and the underlying mechanisms for flexibility improvements.

Trial registration: ClinicalTrials.gov, identifier: NCT02919527. Registered on 27 September 2016.

Keywords: Foam rolling, Self-myofascial release, Flexibility, Tissue stiffness, Connective tissue, Fascia, Ultrasound, Crosscorrelation

\section{Background}

Self-myofascial release (SMR) is an intensive self-treatment with rigid foam rollers and other small handheld tools based on the exertion of compressive force to the soft tissue. Aiming to tackle dysfunctions of the skeletal muscle and connective tissue, it claims to mimic the effects of manual therapy techniques. Recent studies indicate that SMR, inter alia, improves range of motion (ROM) [1-13] without concurrent decrease in neuromuscular performance $[1,2,5$, 10-12]. In addition to neuronal mechanisms, such as increased stretch tolerance $[1,3,4]$, flexibility increases might be attributed to acute morphological adaptations:

First, the fasciae surrounding the muscles of the lower extremity are composed of multiple fibrous layers. Loose

\footnotetext{
* Correspondence: krause@sport.uni-frankfurt.de

Department of Sports Medicine, Institute of Sport Science, Goethe University Frankfurt, Ginnheimer Landstraße 39, 60487 Frankfurt am Main, Germany
}

connective tissue enriched with hyaluronic acid $[14,15]$ allows these layers to slide against each other during motion (e.g., contraction or elongation of the underlying muscle) [14]. Several authors assume a positive effect of SMR on fascial sliding properties, e.g., through breaking up adhesions or loosening cross-links $[10,16]$.

Another hypothesized morphological consequence of SMR is the alteration of passive tissue stiffness, as occurs after static stretching [17-22]. A plethora of studies have demonstrated the existence of myofibroblasts (and their ability to impact stiffness) in fascia [23, 24]. Moreover, according to in vitro experiments, fascial hydration has been shown to alter biomechanical tissue properties [25]. Compression of the muscle and the surrounding fascial tissue (as occurs by the use of a foam roller) might hence stimulate contractile cell activity, affect tissue hydration $[10,16]$ and microarchitecture of cell 
cytoskeleton [26] or muscle filament mechanical properties [27] and thereby alter tissue stiffness. Although these mechanisms seem plausible, there is no scientific evidence for these assumptions. Most studies focus solely on functional parameters (e.g., flexibility, strength, recovery) in practice-based settings. However, knowledge of the underlying physiological processes would allow a more effective selection of therapeutic and performancerelated indications. The aim of the intended study is to evaluate the acute effects of SMR on the passive tissue stiffness of the anterior thigh muscles and the sliding properties of the associated fasciae. We hypothesize, that (1) SMR is able to decrease passive stiffness in the same manner as static stretching [17-22], that (2) increased interlayer sliding of fascial layers occurs following treatment and (3) that these processes are associated with an increase in joint flexibility.

\section{Methods}

\section{Study design}

The study will adopt a randomized crossover design. After signing informed consent prior to study enrollment, healthy participants receive all of the following interventions in a permutated random order:

1. One session of $2 \times 60 \mathrm{~s}$ of SMR at the anterior thigh

2. One session of $2 \times 60 \mathrm{~s}$ of passive static stretching of the muscles at the anterior thigh

3. No intervention

At least 2 days prior to the experimental conditions, participant receive a standardized familiarization session including the testing procedure and an introduction to the SMR intervention to minimize learning effects. Before each intervention, main outcomes are measured. Initial data collection is followed by a 15 -min passive break to prevent the measurement procedure to overlie possible treatment effects. Immediately after the intervention or control condition, post-intervention outcome parameters are collected (see Additional file 1 and Fig. 1). All experimental trials will be performed at the same time of day $( \pm 2 \mathrm{~h})$ for each subject. A period of at least 3 days serves as a wash-out phase between the three experimental testing sessions [22].

\begin{tabular}{|c|c|c|c|c|c|}
\hline \multirow[b]{3}{*}{ TIMEPOINT } & \multicolumn{5}{|c|}{ STUDY PERIOD } \\
\hline & \multirow{2}{*}{$\begin{array}{c}\text { Enrolment } \\
\text { Pre } \\
\text { Intervention }\end{array}$} & \multirow{2}{*}{$\begin{array}{c}\text { Allocation } \\
\text { TO }\end{array}$} & \multicolumn{3}{|c|}{ Post-allocation } \\
\hline & & & $\begin{array}{c}\text { Experimental } \\
\text { session } 1\end{array}$ & $\begin{array}{c}\text { Experimental } \\
\text { session } 2\end{array}$ & $\begin{array}{c}\text { Experimental } \\
\text { session } 3\end{array}$ \\
\hline \multicolumn{6}{|l|}{ ENROLMENT: } \\
\hline \multirow{2}{*}{$\begin{array}{l}\text { Eligibility screen } \\
\text { Informed consent }\end{array}$} & $X$ & & & & \\
\hline & $X$ & & & & \\
\hline Allocation & & $X$ & & & \\
\hline \multicolumn{6}{|l|}{ INTERVENTIONS: } \\
\hline SMR & & & $X^{*}$ & $X^{*}$ & $X^{*}$ \\
\hline & & & $X^{*}$ & $X^{*}$ & $X^{*}$ \\
\hline $\begin{array}{r}\text { Control (no } \\
\text { intervention) }\end{array}$ & & & $X^{*}$ & $X^{*}$ & $X^{*}$ \\
\hline \multicolumn{6}{|l|}{ ASSESSMENTS: } \\
\hline \multirow{2}{*}{$\begin{array}{r}\text { Anthropometric data } \\
\text { Passive Resistive } \\
\text { Torque \& tissue } \\
\text { stiffness }\end{array}$} & & & $x$ & & \\
\hline & & & $X$ & $x$ & $X$ \\
\hline \multirow{2}{*}{$\begin{array}{r}\begin{array}{r}\text { US evaluation / fascial } \\
\text { sliding }\end{array} \\
\text { First stretch Sensation }\end{array}$} & & & $x$ & $x$ & $x$ \\
\hline & & & $x$ & $x$ & $\mathrm{X}$ \\
\hline $\begin{array}{r}\text { Maximal ROM } \\
\text { (active \& passive) }\end{array}$ & & & $X$ & $x$ & $x$ \\
\hline
\end{tabular}

Fig. 1 Standard Protocol Items: Recommendations for Interventional Trials (SPIRIT) figure 
The study was approved by the local Ethics Committee of the Faculty of Psychology and Sport Science (GoetheUniversity Frankfurt). The collection, transfer, storing and analyses of personal data during the trial is in accordance with applicable law. Data are collected at the Department of Sports Medicine, recorded on paper or electronically and treated confidentially. Data transfer requires pseudonymization and is restricted to the principal investigator, study physicians and the competent Ethics Committee for the assessment of study results and adverse events.

The protocol was written in accordance to the Standard Protocol Items: Recommendations for Interventional Trials (SPIRIT) guidelines, a copy of the SPIRIT Checklist has been included as Additional file 2 .

\section{Inclusion/exclusion criteria}

Subjects are eligible for the trial if they meet the following criteria:

- Age between 20 and 40 years

- No history of orthopedic injuries in the lower extremity in the last 12 months

Subjects are ineligible if they have any of the following criteria:

- Any history of psychiatric, cardiovascular, endocrine, neurological or metabolic disorders

- Any current medication that might affect pain perception or proprioception

- Muscle soreness

- Pregnancy/nursing period

- Nonspecific musculoskeletal disorders

\section{Sample size calculation}

To determine the required sample size, an a priori sample size calculation was performed using $G$ *Power ( $G$ *Power, Version 3.1, Heinrich-Heine University Düsseldorf, Germany). Based on previous studies on the effect of static stretching on tissue stiffness [21], we expect a medium effect $\left(f^{2}=0.25 ; \alpha=.05\right.$ and $\left.\beta=.80\right)$. Considering the omnibus testing $(2 \times 3$ repeated measurements ANOVA/ Friedman test), calculated sample size was $n=42$. A $10 \%$ dropout rate assumed and taking into account our crossover study design, the sample size to be recruited is $n=16$ participants.

\section{Randomization}

A balanced permutation randomization sequence of treatment orders is generated using an electronic randomization algorithm (www.randomization.com). Body side of treatment is randomized using the same algorithm.
Randomization is equivalent to the order of study inclusion.

\section{Interventions}

Both interventions consist of two 60-s bouts of either dynamic SMR with a foam roller or static stretching of the myofascial tissue of the anterior thigh. The SMR intervention is performed in the prone position. The participants are instructed to place their body weight on a polypropylene foam roller with a length of $30 \mathrm{~cm}$ and a diameter of $15 \mathrm{~cm}$ (Blackroll, Bottighofen, Switzerland). Applying pressure to the tissue of the anterior thigh, they perform a rolling motion from the proximal aspect of the thigh (inferior to the anterior superior iliac spine) to the knee (see Additional file 3). Once the foam roller reaches the superior border of the patella, participants are instructed to return to the starting position and continue the sequence for the remainder of the $60 \mathrm{~s}[5,7]$. The rolling frequency is standardized using a metronome set at 60 beats per minute (bpm). Participants are instructed to roll at a velocity of two metronome beats (thus, $2 \mathrm{~s}$ ) for each rolling direction, resulting in 15 complete rolling cycles in $60 \mathrm{~s}$ $(0.25 \mathrm{~Hz})$. Intensity of pressure is controlled subjectively with a target Numerical Rating Scale (NRS) rating of 7/10 (0 representing no discomfort and 10 representing maximal discomfort) during the intervention. After a 30-s break in a relaxed prone position, participants perform a second bout.

Similar to SMR, also passive static stretching of the anterior thigh muscles is performed in the prone position with a pre-stretch of the hip $\left(200^{\circ}\right.$ in total) using a bed wedge with a $20^{\circ}$ inclination. In this position, the investigator performs a passive static stretching maneuver by manually flexing the knee of the subject while continuously controlling for secondary movement of the lumbar spine. Stretch intensity is adjusted according to the feedback of the subject (target NRS rating of $7 / 10$ ). The position is held for $60 \mathrm{~s}$, followed by a 30-s rest in a relaxed position and a second bout of stretching at the same target intensity for $60 \mathrm{~s}$.

\section{Outcomes \\ Main outcomes}

Passive resistive torque (PRT) Passive resistive torque of the quadriceps muscle-tendon unit is evaluated using a computerized isokinetic dynamometer (Biodex system 3 Pro, Biodex Medical, Shirley, NY, USA). The participant is placed in a standardized position on the seat of the dynamometer (see Additional file 4). The pelvis as well as the thigh of the tested leg are fixed with restriction straps to minimize secondary movement. The opposite hip is fixed at $90^{\circ}$ flexion to limit pelvic and 
lumbar motion. The knee axis is aligned with the rotational axis of the dynamometer.

To obtain PRT, the lower leg is moved from full knee extension $\left(0^{\circ}\right)$ to maximal achievable knee flexion angle with an angular velocity of $5 \% \mathrm{~s}$ in passive mode of the dynamometer. Torque $(\mathrm{T})$ and angle $(\theta)$ are recorded at $100 \mathrm{~Hz}$. This procedure has been described as a reliable method to evaluate passive tissue properties for various positions and muscles (intraclass correlation coefficient (ICC) ranging from 0.88 to 1.00) [28-33]. Torque data is gravity corrected and filtered using a Butterworth, zerolag, fourth-order low-pass filter with a $10-\mathrm{Hz}$ cutoff frequency [22].

Tissue stiffness A fourth-order polynomial (FOP) model is fitted on the T- $\theta$ data (and stiffness is calculated using the slope of the FOP model $[34,35]$. Passive resistive torque as well as stiffness values from four angles during the last $13^{\circ}$ of passive tissue tensioning $\left(1^{\circ}, 5^{\circ}, 9^{\circ}\right.$ and $\left.13^{\circ}\right)$ are calculated and serve as a quantification of resistance and stiffness during passive motion [22].

To monitor muscle activity, surface electromyography (sEMG) is used with two surface electrodes (Ambu Blue Sensor, Ambu GmbH, Bad Nauheim, Germany) placed on the head of the M. rectus femoris muscle with an 8$\mathrm{mm}$ inter-electrode distance and one reference electrode on the patella, according to SENIAM recommendations [36]. Participants are provided with live biofeedback of muscle activity to prevent involuntary muscle contraction.

Fascial sliding While assessing PRT, the probe of a high-resolution ultrasound (US) device (Siemens Acuson X300, Siemens Healthcare GmbH, Erlangen, Germany) is positioned on the thigh (for details, see below). Sliding of fascial layers is quantified with a frame-by-frame, cross-correlation algorithm of the generated US images obtained during the passive movement. The crosscorrelation method developed in MATLAB (The MathWorks, Inc, Natick, MA, USA) by Dilley and colleagues [37] is used to calculate the correlation coefficient between the pixel gray levels for selected rectangleshaped regions of interest (ROIs) in two adjacent images. The pixel shift providing the maximum correlation coefficient corresponds to the relative movement between two frames [37]. The method has been extensively used to quantify nerve movement and represents a reliable method to quantify tissue movement in vivo (ICC ranging from 0.70 to 0.99 ) [37-44].

The linear array US transducer used $(4-11.4-\mathrm{MHz}$, 38.4-mm footprint) is placed on the proximal third of the muscle belly of the M. rectus femoris and sequences of $20 \mathrm{~s}$ are captured at 10 frames/s during passive knee flexion (starting at $0^{\circ}$ until $100^{\circ}$ of knee flexion at $5^{\circ} / \mathrm{s}$ ).
US transducer location is marked on the skin with a permanent marker. Participants are instructed to renew the marker on a daily basis to ensure equal transducer placement at all three testing sessions. Six ROIs are placed on the superficial and deep layers of the fascia lata, respectively, to quantify sliding of these layers during passive stretching of the underlying muscle (see Additional file 5). Maximal lateral movement of ROIs/ fascial layers is calculated and analyzed as a quantification of fascial sliding.

\section{Secondary outcomes}

Flexibility and ROM Three parameters representing flexibility and ROM are assessed. The position of the first stretch sensation is quantified using the isokinetic dynamometer in the above-described position. In passive mode, the knee is flexed from full extension to flexion at $5 \%$. The subject uses a switch to stop the passive movement at the position of the first stretch sensation.

Maximal active as well as passive knee flexion ROM in the sagittal plane is assessed in prone lying with a 3D ultrasonographic movement analysis system (zebris CMS20, zebris Medical GmbH, Isny, Germany). Inter- as well as intra-rater reliability have been described as good to excellent ( $r$ between .84 and .96) [45]. A triplet of ultrasonographic markers is placed on the lower leg, a second triplet is placed as a reference on the thigh. In this position, participants are instructed to perform three consecutive active knee flexion-extension cycles at a self-selected velocity. Subsequently, the investigator performs three passive knee flexion-extension cycles. Movements are recorded in three dimensions at $20 \mathrm{~Hz}$, and maximal active as well as passive knee flexion ROM in the sagittal plane can be calculated as the maximal displacement relative to the starting position recorded by the US markers.

\section{Statistical analysis}

The software SPSS (version 22.0, SPSS Inc., Chicago, IL, USA) is used for statistical analyses. All calculation are performed after checking the underlying assumptions for (1) parametric or (2) nonparametric testing. Statistically significant differences between pre and post measurements, as well as the three conditions (SMR, stretching, control), are tested with (a) a $2 \times 3$ repeated measurements ANOVA followed by LSD post hoc analyses or (b) Friedman test followed by Dunn-Bonferroni tests. Associations between measures of tissue stiffness, respectively fascial sliding and $\mathrm{ROM}$ measures are evaluated with (a) Pearson or (b) Spearman correlation analyses. The level of statistical significance is set to $\alpha<$ 0.05 . Due to the explorative design of the study, an 
alpha-level correction will not be performed for the multiple hypotheses testing.

\section{Discussion}

The use of foam rollers in the context of treatment and training of fascial tissues has gained considerable popularity in the last decade. Current research suggests that SMR techniques can improve ROM, but the effects on passive tissue stiffness and fascial sliding as possible influencing factors have not been evaluated yet.

Knowledge about these effects will allow a better understanding of, and provide further evidence on, the local effects of SMR techniques and the factors leading to improvements in ROM. In contrast to static stretching, foam rolling does not seem to negatively affect neuromuscular performance, so the acute biomechanical mechanisms for increases in flexibility might differ.

The results of the intended study will have several implications for clinical practice and the implementation of SMR techniques into therapy and training. Knowledge of the effect on passive tissue stiffness and fascial sliding allows the clinician to determine the optimal timing for the use of SMR during warm-up before competition or during therapy to restore normal ROM.

\section{Trial status}

At the time of submission of this manuscript, recruitment is ongoing.

\section{Additional files}

Additional file 1: Study flow chart. (JPG $2046 \mathrm{~kb}$ )

Additional file 2: SPIRIT Checklist. (DOC $120 \mathrm{~kb}$ )

Additional file 3: Illustration of the self-myofascial release (SMR) intervention. (JPG $2832 \mathrm{~kb}$ )

Additional file 4: Positioning of participants on the isokinetic dynamometer. (JPG $1897 \mathrm{~kb}$ )

Additional file 5: Exemplary (based on a pilot participant) visualization of the results of the Cross-correlation analysis. Description of data: blue boxes: individual regions of interest (ROls), white rectangles: mean movement of all ROls, yellow rectangles: movement of individual ROls. ROls at the beginning of the passive knee flexion (A). Motion of the ROls at the end of the passive knee flexion (B). Resulting line graph of motion of separate ROls (C). (JPG $2079 \mathrm{~kb})$

\section{Abbreviations}

bpm: Beats per minute; FOP: Fourth-order polynomial; NRS: Numerical Rating Scale; PRT: Passive resistive torque; ROM: Range of motion; sEMG: Surface electromyography; SMR: Self-myofascial release; SPIRIT: Standard Protocol Items: Recommendations for Interventional Trials; T: Torque

\section{Acknowledgements}

Not applicable.

\section{Funding}

No external funding.

Availability of data and materials Not applicable.

\section{Authors' contributions}

The trial was developed by FK, JW, DN, LV and WB. FK wrote the first draft of the manuscript and will carry out recruitment and data collection. JW and DN assisted in pilot testing and selection of outcome parameters as well as statistical analyses. LV and WB provided intellectual contributions to the final, submitted version of the manuscript. All authors revised the manuscript providing critical review and final approval.

\section{Competing interests}

The authors declare that they have no competing interests.

\section{Consent for publication}

Written informed consent was obtained from the participants for publication of their individual details and accompanying images in this manuscript. The consent form is held by the authors and is available for review by the Editor-in-Chief.

\section{Ethics approval and consent to participate}

The study was approved by the local Ethics Committee of the Faculty of Psychology and Sport Science, Goethe-University Frankfurt (number 2016/ 38). All participants provide informed consent prior to study enrollment.

Received: 5 December 2016 Accepted: 24 February 2017

Published online: 09 March 2017

\section{References}

1. Halperin I, Aboodarda SJ, Button DC, Andersen LL, Behm DG. Roller massager improves range of motion of plantar flexor muscles without subsequent decreases in force parameters. Int J Sports Phys Ther. 2014; 9:92-102

2. Behara B, Jacobson BH. The acute effects of deep tissue foam rolling and dynamic stretching on muscular strength, power and flexibility in Division I Lineman. J Orthop Trauma. 2015. doi:10.1519/JSC.0000000000001051.

3. Bradbury-Squires DJ, Noftall JC, Sullivan KM, Behm DG, Power KE, Button DC. Roller-massager application to the quadriceps and knee-joint range of motion and neuromuscular efficiency during a lunge. J Athl Train. 2015;50: 133-40. doi:10.4085/1062-6050-49.5.03.

4. Junker $D$, Stögg| T. The foam roll as a tool to improve hamstring flexibility. J Strength Cond Res. 2015. doi:10.1519/JSC.0000000000001007.

5. MacDonald GZ, Penney, Michael DH, Mullaley ME, Cuconato AL, Drake, Corey DJ, Behm DG, Button DC. An acute bout of self-myofascial release increases range of motion without a subsequent decrease in muscle activation or force. J Strength Cond Res. 2013;27:812-21. doi:10.1519/JSC. Ob013e31825c2bc1.

6. Mohr AR, Long BC, Goad CL. Effect of foam rolling and static stretching on passive hip-flexion range of motion. J Sport Rehabil. 2014:23:296-9. doi:10. 1123/jsr.2013-0025.

7. Vigotsky AD, Lehman GJ, Contreras B, Beardsley C, Chung B, Feser EH. Acute effects of anterior thigh foam rolling on hip angle, knee angle, and rectus femoris length in the modified Thomas test. Peer J. 2015;3:e1281. doi:10. 7717/peerj.1281.

8. Sullivan KM, Silvey, Dustin BJ, Button DC, Behm DG. Roller-massager application to the hamstrings increases sit-and-reach range of motion within five to ten seconds without performance impairments. Int J Sports Phys Ther. 2013;8:228-36.

9. Škarabot J, Beardsley C, Stirn I. Comparing the effects of self-myofascial release with static stretching on ankle range-of-motion in adolescent athletes. Int J Sports Phys Ther. 2015;10:203-12.

10. Beardsley C, Škarabot J. Effects of self-myofascial release: a systematic review. J Bodyw Mov Ther. 2015;19:747-58. doi:10.1016/j.jbmt.2015.08.007.

11. Cheatham SW, Kolber MJ, Cain M, Lee M. The effects of self myofascial release using a foam roller or roller massager on joint range of motion, muscle recovery and performance: a systematic review. Int J Sports Phys Ther. 2015:10:827-38.

12. Schroeder AN, Best TM. Is self myofascial release an effective preexercise and recovery strategy? A literature review. Curr Sports Med Rep. 2015;14: 200-8. doi:10.1249/JSR.0000000000000148.

13. Kelly S, Beardsley C. Specific and cross-over effects of foam rolling on ankle dorsiflexion range of motion. Int J Sports Phys Ther. 2016;11:544-51. 
14. Stecco C, Porzionato A, Lancerotto L, Stecco A, Macchi V, Day JA, de Caro R. Histological study of the deep fasciae of the limbs. J Bodyw Mov Ther. 2008; 12:225-30. doi:10.1016/j.jbmt.2008.04.041.

15. Stecco C, Stern R, Porzionato A, Macchi V, Masiero S, Stecco A, de Caro R. Hyaluronan within fascia in the etiology of myofascial pain. Surg Radiol Anat. 2011:33:891-6. doi:10.1007/s00276-011-0876-9.

16. Schleip R, Müller DG. Training principles for fascial connective tissues: scientific foundation and suggested practical applications. J Bodyw Mov Ther. 2013;17:103-15. doi:10.1016/j.jbmt.2012.06.007.

17. Magnusson SP, Simonsen EB, Aagaard P, Gleim GW, McHugh MP, Kjaer M. Viscoelastic response to repeated static stretching in the human hamstring muscle. Scand J Med Sci Sports. 1995;5:342-7.

18. Magnusson SP, Simonsen EB, Aagaard P, Kjaer M. Biomechanical responses to repeated stretches in human hamstring muscle in vivo. Am J Sports Med. 1996;24:622-8

19. Nordez A, Cornu C, McNair P. Acute effects of static stretching on passive stiffness of the hamstring muscles calculated using different mathematical models. Clin Biomech (Bristol, Avon). 2006;21:755-60. doi:10.1016/j. clinbiomech.2006.03.005.

20. McNair PJ, Dombroski EW, Hewson DJ, Stanley SN. Stretching at the ankle joint: viscoelastic responses to holds and continuous passive motion. Med Sci Sports Exerc. 2001;33:354-8.

21. Whatman C, Knappstein A, Hume P. Acute changes in passive stiffness and range of motion post-stretching. Phys Ther Sport. 2006;7:195-200. doi:10. 1016/j.ptsp.2006.07.002

22. Ryan ED, Beck TW, Herda TJ, Hull HR, Hartman MJ, Costa PB, et al. The time course of musculotendinous stiffness responses following different durations of passive stretching. J Orthop Sports Phys Ther. 2008;38:632-9. doi:10.2519/jospt.2008.2843.

23. Staubesand J, Li Y. Zum Feinbau der Fascia cruris mit besonderer Berücksichtigung epi- und intrafaszialer Nerven. Manuelle Medizin. 1996;34: 196-200.

24. Schleip R, Klingler W, Lehmann-Horn F. Active fascial contractility: fascia may be able to contract in a smooth muscle-like manner and thereby influence musculoskeletal dynamics. Med Hypotheses. 2005;65:273-7. doi:10.1016/j. mehy.2005.03.005

25. Schleip R, Duerselen L, Vleeming A, Naylor IL, Lehmann-Horn F, Zorn A, et al. Strain hardening of fascia: static stretching of dense fibrous connective tissues can induce a temporary stiffness increase accompanied by enhanced matrix hydration. J Bodyw Mov Ther. 2012;16:94-100. doi:10.1016/ j.jbmt.2011.09.003.

26. Fletcher DA, Mullins RD. Cell mechanics and the cytoskeleton. Nature. 2010; 463:485-92. doi:10.1038/nature08908.

27. Chaudhuri O, Parekh SH, Fletcher DA. Reversible stress softening of actin networks. Nature. 2007:445:295-8. doi:10.1038/nature05459.

28. Porter MM, Andersson M, Hellstrom U, Miller M. Passive resistive torque of the plantar flexors following eccentric loading as assessed by isokinetic dynamometry. Can J Appl Physiol. 2002;27:612-7.

29. Gajdosik RL, Vander Linden DW, Williams AK. Influence of age on length and passive elastic stiffness characteristics of the calf muscle-tendon unit of women. Phys Ther. 1999;79:827-38.

30. Bressel E, Larsen BT, McNair PJ, Cronin J. Ankle joint proprioception and passive mechanical properties of the calf muscles after an Achilles tendon rupture: a comparison with matched controls. Clin Biomech (Bristol, Avon). 2004;19:284-91. doi:10.1016/j.clinbiomech.2003.12.008.

31. Nordez A, Casari P, Cornu C. Accuracy of Biodex system 3 pro computerized dynamometer in passive mode. Med Eng Phys. 2008;30:880-7. doi:10.1016/j. medengphy.2007.11.001

32. Araujo VL, Carvalhais VO, Souza TR, Ocarino JM, Goncalves GG, Fonseca ST. Validity and reliability of clinical tests for assessing passive ankle stiffness. Rev Bras Fisioter. 2011;15:166-73.

33. Carvalhais, Viviane Otoni do Carmo, Araújo VLd, Souza TR, Gonçalves GGP, Ocarino JdM, Fonseca ST. Validity and reliability of clinical tests for assessing hip passive stiffness. Manual Therapy. 2011;16:240-5. doi:10.1016/j.math. 2010.10.009

34. Nordez A, McNair P, Casari P, Cornu C. Acute changes in hamstrings musculo-articular dissipative properties induced by cyclic and static stretching. Int J Sports Med. 2008;29:414-8. doi:10.1055/s-2007-964980.

35. Nordez A, McNair PJ, Casari P, Cornu C. Static and cyclic stretching: their different effects on the passive torque-angle curve. J Sci Med Sport. 2010;13: 156-60. doi:10.1016/j.jsams.2009.02.003.
36. Hermens HJ, Freriks B, Disselhorst-Klug C, Rau G. Development of recommendations for SEMG sensors and sensor placement procedures. J Electromyogr Kinesiol. 2000;10:361-74.

37. Dilley A, Greening J, Lynn B, Leary R, Morris V. The use of crosscorrelation analysis between high-frequency ultrasound images to measure longitudinal median nerve movement. Ultrasound Med Biol. 2001;27:1211-8

38. Boyd BS, Gray AT, Dilley A, Wanek L, Topp KS. The pattern of tibial nerve excursion with active ankle dorsiflexion is different in older people with diabetes mellitus. Clin Biomech. 2012;27:967-71. doi:10.1016/j.clinbiomech. 2012.06.013

39. Dilley A, Summerhayes C, Lynn B. An in vivo investigation of ulnar nerve sliding during upper limb movements. Clin Biomech (Bristol, Avon). 2007;22: 774-9. doi:10.1016/j.clinbiomech.2007.04.004.

40. Carroll M, Yau J, Rome K, Hing W. Measurement of tibial nerve excursion during ankle joint dorsiflexion in a weight-bearing position with ultrasound imaging. J Foot Ankle Res. 2012;5:1. doi:10.1186/1757-1146-5-5.

41. Coppieters MW, Hough AD, Dilley A. Different nerve-gliding exercises induce different magnitudes of median nerve longitudinal excursion: an in vivo study using dynamic ultrasound imaging. J Orthop Sports Phys Ther. 2009;39:164-71. doi:10.2519/jospt.2009.2913.

42. Ellis RF, Hing WA, McNair PJ. Comparison of longitudinal sciatic nerve movement with different mobilization exercises: an in vivo study utilizing ultrasound imaging. J Orthop Sports Phys Ther. 2012:42:667-75. doi:10.2519/ jospt.2012.3854

43. Julius A, Lees R, Dilley A, Lynn B. Shoulder posture and median nerve sliding. BMC Musculoskelet Disord. 2004;5:1. doi:10.1186/1471-2474-5-23.

44. Ellis R, Hing W, Dilley A, McNair P. Reliability of measuring sciatic and tibial nerve movement with diagnostic ultrasound during a neural mobilisation technique. Ultrasound Med Biol. 2008;34:1209-16. doi:10.1016/j. ultrasmedbio.2008.01.003.

45. Natalis M, Konig A. Noninvasive, accurate and reliable measurement of cervical spine motion with a 3D real-time ultrasound motion analyzer. Ultraschall Med. 1999;20:70-3. doi:10.1055/s-1999-14237.

\section{Submit your next manuscript to BioMed Central and we will help you at every step:}

- We accept pre-submission inquiries

- Our selector tool helps you to find the most relevant journal

- We provide round the clock customer support

- Convenient online submission

- Thorough peer review

- Inclusion in PubMed and all major indexing services

- Maximum visibility for your research

Submit your manuscript at www.biomedcentral.com/submit 